\title{
Fiksasi fraktur kominutif os femur menggunakan intramedullary pin dan wire pada kucing domestik (Felis domestica)
}

\author{
Erwin $^{1}{ }^{*}$, Rusli $^{1}$, Etriwati $^{2}$, Dirga Rizki Imanda ${ }^{3}$, Hanif Fadli $^{4}$ \\ ${ }^{1}$ Laboratorium Klinik dan Bedah, Fakultas Kedokteran Hewan, Universitas Syiah Kuala, Banda Aceh \\ ${ }^{2}$ Laboratorium Patologi, Fakultas Kedokteran Hewan, Universitas Syiah Kuala, Banda Aceh \\ ${ }^{3}$ Program Pendidikan Profesi Dokter Hewan, Fakultas Kedokteran Hewan, Universitas Syiah Kuala, Banda Aceh \\ ${ }^{4}$ Rumah Sakit Hewan Provinsi Sumatra Barat, Padang
}

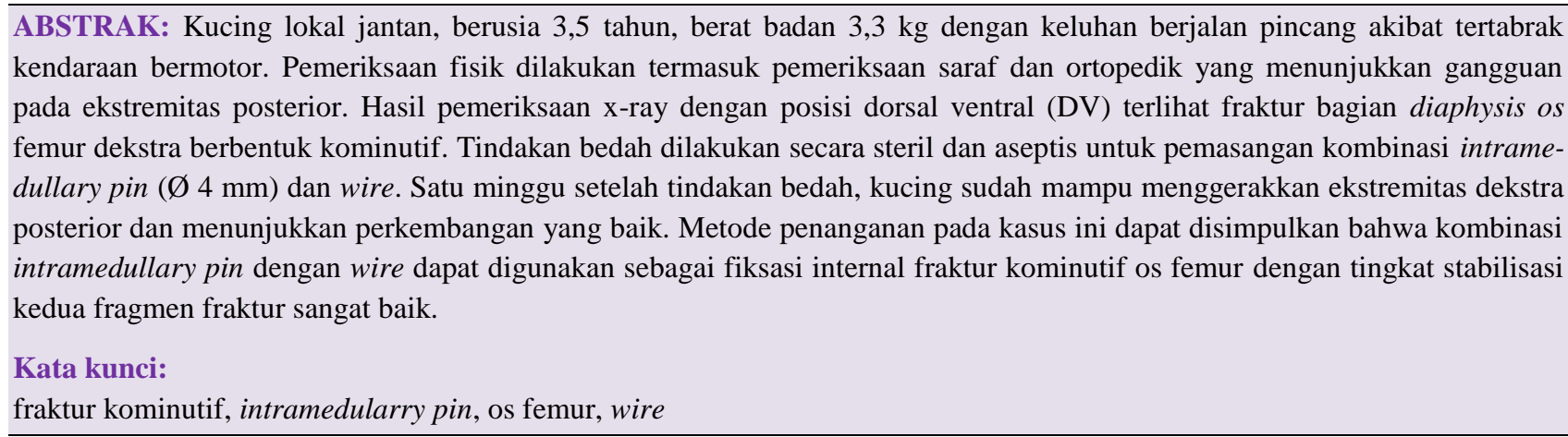

\section{- PENDAHULUAN}

Fraktur adalah kerusakan jaringan tulang yang mengakibatkan tulang kehilangan kontinuitas dan keseimbangan. Fraktur os femur dapat terjadi pada bagian metaphysis, diaphysis dan epiphysis (Tercanlioglu dan Sarierler 2009, Shiju et al. 2010). Prinsip dasar penanganan fraktur adalah mengembalikan posisi anatomis kedua fragmen fraktur melalui fiksasi tertutup atau fiksasi terbuka. Alat fiksasi internal yang sering digunakan dalam penanganan fraktur antara lain intramedullary pin, plate, screw dan wire (Mafi et al. 2014; Mwangi and Mande 2012).

\section{- KASUS}

Seekor kucing domestik jantan berusia 3,5 tahun dengan berat badan $3,3 \mathrm{~kg}$ dibawa ke rumah sakit hewan dengan gejala klinis gangguan pada ekstremitas posterior. Anamnesis dari pemilik hewan mengatakan bahwa kucingnya terlindas kendaraan bermotor sehari sebelumnya. Pemeriksaan fisik dimulai dari bagian anterior ke posterior meliputi pemeriksaan mata, hidung, mulut, telinga, kelenjar limfe, saluran respirasi, saluran kardiovaskular, saluran pencernaan, saluarn urinaria dan saluran reproduksi tidak menunjukkan perubahan. Pemeriksaan neurologi meliputi propriosepsis kesadaran, upper motor neuron dan lower motor neuron tidak menunjukkan gangguan pada saraf yang menginervasi bagian posterior. Pemeriksaan ortopedik menunjukkan kucing tidak bisa berjalan dan nyeri di area ekstremitas posterior. Pemeriksaan profil darah menunjukkan semua nilai parameter berada dalam kisaran normal. Pemeriksaan profil darah sebelum dan setelah bedah bertujuan untuk mengetahui kondisi sistemik tubuh kucing. Pemeriksaan profil darah meliputi: jumlah eritrosit, leukosit total dan differensial, hemoglobin, hematokrit, trombosit (Erwin et al. 2017).

Pemeriksaan radiografi sebagai langkah konfirmasi untuk melihat area dan bentuk patahan tulang. Kucing diberikan diazepam (Valisanbe®, Sanbe Farma, Indonesia) 2 mg PO sebagai sedatif untuk pengambilan foto $\mathrm{x}$-ray dorso ventral. Hasil foto x-ray menunjukkan patahan berbentuk comminuted pada diaphysis os femur sebagaimana disajikan pada Gambar 1.

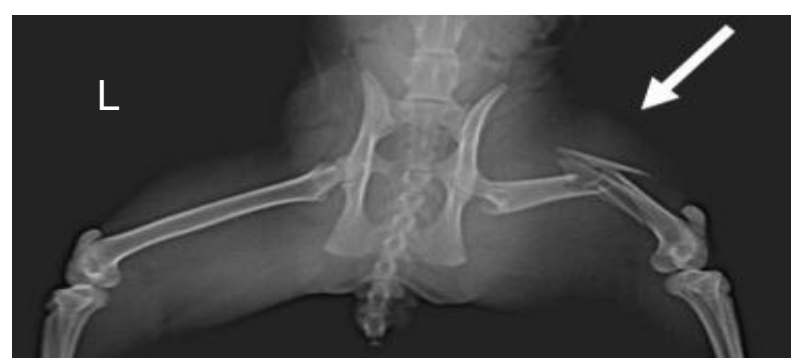

Gambar 1 Foto x-ray fraktur femur sebelum bedah pada kucing dengan posisi dorso ventral (DV), fraktur berbentuk communited pada diaphysis os femur (tanda panah putih)

Diterima: 23-10-2018 | Direvisi: 12-11-2018 | Disetujui: 16-11-2018

(C) 2018 CC-BY-SA. Ini adalah artikel Open Access yang didistribusikan berdasarkan ketentuan dari Creative Commons Attribution ShareAlike 4.0 International License (https://creativecommons.org/licenses/by-sa/4.0/). 


\section{- HASIL DAN PEMBAHASAN}

Penanganan fraktur menggunakan metode ORIF (Open Reduction Internal Fixation). Metode ORIF merupakan reposisi dengan tindakan bedah yang diikuti dengan fiksasi internal. Kucing diberikan premedikasi atropin sulfat (Atropine ${ }^{\circledR}$, Ethica, Indonesia) $0,25 \mathrm{mg} / \mathrm{kg}$ BB SC. Anestesi kombinasi ketamin $2 \%$ (Ketamil®, Troy Laboratories PTY Limited, Australia) $10 \mathrm{mg} / \mathrm{kg}$ BB IM dengan xylazine 2\% (Xyla®, Interchemie, Holland) 1 $\mathrm{mg} / \mathrm{kg}$ BB IM (Sayuti et al. 2016). Tindakan bedah dimulai dengan insisi kulit sepanjang kraniolateral os femur mulai dari trokhanter ke arah os patela, preparasi jaringan subkutis, muskulus vastus lateralis dan vastus intermedius, dengan hati-hati fascia longgar dan tulang dibebaskan. Kedua fragmen fraktur di reposisi, difiksasi menggunakan intramedullary pin diameter $4 \mathrm{~mm}$ dan segmen patahan fraktur diikat menggunakan wire (Gambar 2a), Gambar 2b menyajikan foto $\mathrm{x}$-ray posisi right lateral recumbency.

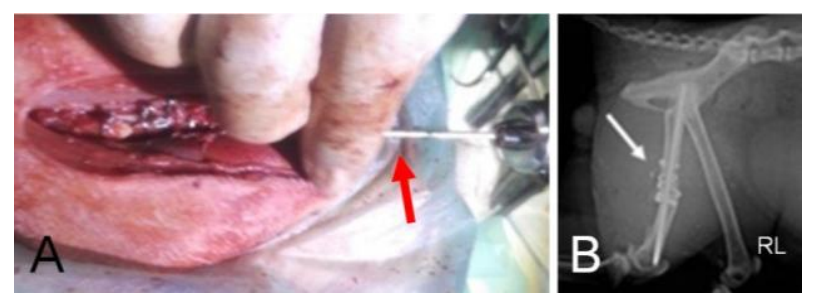

Gambar 2 Tindakan bedah pemasangan intramedullary pin dan wire (panah merah) (A) dan foto $\mathrm{x}$-ray (panah putih) (B).

Perawatan pascabedah dengan pemberian antibiotik spektrum luas dan analgesik non steroid selama 14 hari dan menghindari pelepasan kucing. Intramedullary pin menghasilkan stabilisasi yang baik antara kedua fragmen fraktur. Diameter intramedullary pin harus tepat sesuai dengan berat badan hewan dan ukuran kanalis medularis, sehingga dapat menahan beban dari hewan itu sendiri. Penggunaan intramedullary pin dengan diameter yang sesuai dapat meminimalkan komplikasi dan defleksi atau pembelokan. Intramedullary pin umumnya diproduksi dalam beberapa diameter yaitu 3-7,5 mm (Chanana et al. 2018; Saglam and Kaya 2004). Penggunaan intramedullary pin dengan diameter 70-80 \% dari diameter kanalis medularis menghasilkan kesembuhan yang lebih baik. Sedangkan diameter 30-40 \% sering menyebabkan pin terlepas dan menghasilkan fiksasi tidak baik (Saglam and Kaya 2004; Syafruddin et al. 2004).

Pasien mampu berjalan dengan menyentuh kaki ke tanah hari ke 3-5 pascabedah. Tersebut masa perkembangan penting untuk menghindari terjadinya komplikasi dan gangguan ekstremitas posterior. Proses persembuhan fraktur dipengaruhi oleh beberapa faktor lokal dan sistemik. Faktor persembuhan lokal meliputi lokasi fraktur, jenis tulang yang mengalami fraktur, reposisi anatomis dan immobilasi yang stabil, adanya kontak antar fragmen, ada tidaknya infeksi serta derajat keparahan fraktur. Sedangkan faktor sistemik adalah keadaan umum pasien, umur, malnutrisi dan penyakit sistemik (Brunner and Suddart 2002).

Kesembuhan fraktur os femur diawali proliferasi fibroblas oleh sel-sel periosteum dan endostium. Sel-sel osteoblas mengeluarkan matrik interseluler dari kolagen dan polisakarida yang bersatu dengan ion-ion kalsium dan membentuk young callus. Young callus yang terbentuk mengalami maturasi lebih lanjut oleh aktivitas osteoblas dan menjadi tulang dewasa dengan pembentukan lamela-lamela. Pembentukan kalus mulai terjadi hari ke-20 pascabedah. Fase ini berlangsung setelah 4 minggu pascafraktur, namun pada hewan muda dapat berlangsung lebih cepat (Joshi et al. 2010; Mwangi and Mande 2012).

\section{- SIMPULAN}

Kombinasi intramedullary pin dengan wire dapat digunakan sebagai fiksasi internal pada fraktur kominutif os femur dengan tingkat stabilisasi sangat baik.

\section{— INFORMASI PENULIS}

\section{Penulis untuk Korespondensi}

*E: erwin2102@unsyiah.ac.id

Laboratorium Klinik dan Bedah, Fakultas Kedokteran Hewan, Universitas Syiah Kuala, Banda Aceh, Indonesia

\section{- PUSTAKA ACUAN}

Chanana M, Kumar A, Tyagi SP, Singla AK, Sharma A, Farooq UB. 2018. End-threaded intramedullary positive profile screw ended self-tapping pin (Admit pin) - A cost-effective novel implant for fixing canine long bone fractures, Veterinary World. 11(2):181-185.

Erwin E, Gunanti G, Handharyani E, Noviana D. 2017. Blood profile of domestic cat (Felis catus) during skin graft recovery with different period. Jurnal Veteriner. 18(1): 31-37.

Joshi DO, Tank PH, Mahida HK, Dhami MA, Vedpathak HS, Karle AS. 2010. Bone grafting: An overview. Veterinary World. 3(4):198-200.

Mafi R, KhanW, Mafi P, Hindocha S. 2014. Orthopedic approaches to proximal humeral fractures following trauma. The Open Orthopaedics Journal. 8: 437-441.

Mwangi WE, Mande JD. 2012. Case report: Internal fixation of an oblique femoral fracture using cerclage wires and bone plate. University of Nairobi.

Saglam M, Kaya U. 2004. Treatment of proximal tibial fractures by cross pin fixation in dogs. Turk J Vet Anim Sci. 28: 799-805.

Sayuti E, Maulizar R, Syafruddin S, Erwin E, Frengky F, Muttaqien B, Budianto P, Zuraidawati Z. 2016. Effect of ketamine-xylazine and propofol on heart rate and breathing frequency of local male dog (Canis familiaris). Jurnal Medika Veteriner. 10(1):34-36.

Shiju MS, Ganesh R, Ayyappan S, Kumar RS. 2010. Incidence of pectoral limb fractures in dogs: A survey of 331 cases. Tamilnadu Journal of Veterinary and Animal Sciences. 7(2): 94 96.

Stiffler KS. 2004. Internal fracture fixation. Clin Tech Small Anim Pract. 19(3): 105-113.

Syafruddin, Santoso AB, Untoro M. 2004. Gambaran radiografi patah tulang paha setelah pemakaian pin intrameduler pada anjing (Canis familiaris). Jurnal Sain Veteriner. 22(1): 64-67

Tercanlioglu H, Sarierler M. 2009. Femur fractures and treatment options in dogs which brought our clinics. Lucrări stiinłifice medicină veterinară. 13(2): 98-101. 